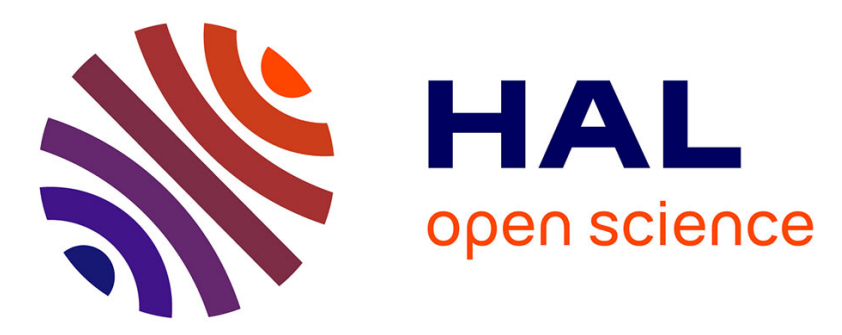

\title{
A Coupled Electrical-Thermal-Mechanical Modeling of Gleeble Tensile Tests for Ultra-High-Strength (UHS) Steel at a High Temperature
}

Changli Zhang, Michel Bellet, Manuel Bobadilla, Houfa Shen, Baicheng Liu

\section{- To cite this version:}

Changli Zhang, Michel Bellet, Manuel Bobadilla, Houfa Shen, Baicheng Liu. A Coupled ElectricalThermal-Mechanical Modeling of Gleeble Tensile Tests for Ultra-High-Strength (UHS) Steel at a High Temperature. Metallurgical and Materials Transactions A, 2010, 41 (9), pp.2304-2317. 10.1007/s11661-010-0310-7 . hal-00527828

\section{HAL Id: hal-00527828}

https://hal-mines-paristech.archives-ouvertes.fr/hal-00527828

Submitted on 9 Mar 2011

HAL is a multi-disciplinary open access archive for the deposit and dissemination of scientific research documents, whether they are published or not. The documents may come from teaching and research institutions in France or abroad, or from public or private research centers.
L'archive ouverte pluridisciplinaire HAL, est destinée au dépôt et à la diffusion de documents scientifiques de niveau recherche, publiés ou non, émanant des établissements d'enseignement et de recherche français ou étrangers, des laboratoires publics ou privés. 


\title{
A Coupled Electrical-Thermal-Mechanical Modeling of Gleeble
}

\section{Tensile Tests for Ultra-High-Strength Steel at a High Temperature}

\author{
Changli Zhang ${ }^{* 1}$, Michel Bellet ${ }^{2}$, Manuel Bobadilla ${ }^{3}$, \\ Houfa Shen ${ }^{1}$, Baicheng Liu ${ }^{1}$ \\ ${ }^{1}$ Key Laboratory for Advanced Materials Processing Technology, Department of Mechanical \\ Engineering, Tsinghua University, 100084 Beijing, P.R. China \\ ${ }^{2}$ Mines-ParisTech - CEMEF, Centre de Mise en Forme des Matériaux, UMR CNRS 7635, BP 207, \\ 06904 Sophia Antipolis, France \\ ${ }^{3}$ ArcelorMittal, Research and Development, Maizières-lès-Metz, France
}

\begin{abstract}
A coupled electrical-thermal-mechanical model is proposed, aiming to the numerical modelling of Gleeble tension tests at high temperature. A multi-domain multi-field coupling resolution strategy is used for the solution of electrical, energy and momentum conservation equations by means of the finite element method. Application to UHS steel is considered. After calibration with instrumented experiments, numerical results reveal that significant thermal gradients prevail in Gleeble tensile steel specimen in both axial and radial directions. Such gradients lead to the heterogeneous deformation of the specimen, which is a major difficulty for simple identification techniques of constitutive parameters, based upon direct estimations of strain, strain rate and stress. The proposed direct finite element coupled model can be viewed as an important achievement for further inverse identification methods, which should be used to identify constitutive parameters for steel at high temperature in the solid state and in the mushy state.
\end{abstract}

Keywords electrical-thermal-mechanical modelling, Gleeble tension test, high temperature, UHS steel

\footnotetext{
* corresponding author, e-mail address: zhangc105@mails.tsinghua.edu.cn
} 


\section{Introduction}

Various defects on as-cast products are often encountered in shape or continuous casting production. Hot tears formed at the end of solidification or cracks formed at lower temperature in the solid state are frequent defects in industrial practice. They can be found at or near the surface, or in the core of products. Such defects cannot be eliminated by post thermomechanical treatments. From many studies, it is known that hot tears, also called solidification cracks, initiate just above solidus temperature in the mushy zone when it is subjected to a tensile state ${ }^{[1]}$. For the prediction of the initiation of such cracks, many hot tearing "macroscopic" criteria have been proposed mostly involving critical stress ${ }^{[2]}$, critical strain ${ }^{[3-5]}$ or critical strain rate ${ }^{[6]}$. Therefore, the mathematical modelling of the formation of such cracks in cast products is a complex task, which should be based upon a reliable prediction of the local thermomechanical state in castings, which requires in turn reliable and accurate constitutive relations for the considered materials, especially at high temperature.

Experimental studies of the rheological behavior of metals have been extensively reported in literature for many years. However, there are quite few papers dealing with the characterization of steels at very high temperature, namely over $1200{ }^{\circ} \mathrm{C}$ and up to the mushy state. The difficulties are mainly caused by the very high level of steel melting point in comparison with non-ferrous metals like aluminum alloys, which demands strict requirements for the experimental devices. Gleeble thermo-simulator systems are efficient tools to the subject, as they provide means for characterizing metals at high temperature, under vacuum, and along complex thermal-mechanical paths ${ }^{[7,8]}$. However, it should be noted that as reported in literature ${ }^{[7-9]}$, thermal gradients always exist at high temperature in Gleeble-type tension or compression specimens. Because the mechanical properties of steel are temperature dependent, such thermal gradients become the source of deformation heterogeneities in specimens. As a consequence, an accurate analysis of Gleeble tension or compression tests, in view of identifying parameters of constitutive equations, cannot be carried out on the basis of the usual assumption of uniform stress, strain-rate and strain in the working zone of the specimen. The identification task must then be based on the inverse methods involving an accurate direct numerical modelling of such tests.

The present paper focuses on the direct modelling of Gleeble tensile tests for steel at high temperature, with the intention of providing a reliable direct numerical simulation of tests for further inverse identification. During Gleeble tension tests, complex phenomena occur concurrently, such as 
electrical, thermal and mechanical phenomena, which are seldom taken into account. Most papers dealing with numerical modelling of Gleeble tests only consider the electrical-thermal problem, like Brown et al. ${ }^{[10]}$; Norris $\&$ Wilson ${ }^{[11]}$; Solek et al. ${ }^{[12]}$, for instance, which are already of great help in the design of Gleeble specimens. In the present study, a coupled electrical-thermal-mechanical model, which is the subject of this work, is described and applied to the direct modelling of the Gleeble tensile tests on steel specimens at high temperature, providing the basis of the automatic inverse identification of constitutive parameters for steels at very high temperature.

\section{Experimental Procedure}

An ultra high strength (UHS) steel is considered in the present study, the main chemical composition of which is: $0.16 \mathrm{wt} \% \mathrm{C}, 0.23 \mathrm{wt} \% \mathrm{Si}, 1.89 \mathrm{wt} \% \mathrm{Mn}$. Cylindrical tensile specimens with 10 mm diameter and $120 \mathrm{~mm}$ length (Figure 1a) have been tested using a Gleeble machine (model 1500D), which is schematically shown in Figure $1 \mathrm{~b}$. The specimen is heated by an alternate current (AC), which is introduced through the copper grips. The vacuum atmosphere in the chamber is maintained at $5 \times 10^{-4}$ torr (about $0.067 \mathrm{~Pa}$ ) to prevent oxidation of the specimen, and also to minimize heat losses by convection. A transparent quartz tube is used to cover the working zone of specimen in order to retain the possible melt.

In a first step, as shown in Figure 2, the specimen is rapidly heated up to $1050{ }^{\circ} \mathrm{C}$ with a heating rate of $15^{\circ} \mathrm{C} / \mathrm{s}$ and held for 1 minute for homogenization. In a second step, it is heated up to the testing temperature (at $2{ }^{\circ} \mathrm{C} / \mathrm{s}$ ), and maintained at the testing temperature for one minute before mechanical loading. During the whole testing period including heating and mechanical loading, the electrical input is monitored according to the temperature measured by the thermocouple welded on the surface of the specimen, at mid-length (TC0 in Figure 1b). In the following of the paper, in the absence of complementary information, the temperatures that are mentioned are those measured or predicted at this location TCO.

In order to get the knowledge of the temperature distribution in the specimen, temperatures are continuously measured at several locations in specifically dedicated tests (see Figure 1a):

- At three locations along the surface of the specimen: mid-length (TC0), $7.5 \mathrm{~mm}$ and $10 \mathrm{~mm}$ from center (TC1 and TC2, respectively). This provides information on the axial temperature gradient. 
In addition, the temperature measurement in position TC0 is used all along the test for the monitoring of the electrical input.

○ In core center on the symmetry axis, in the mid transverse section of the specimen (TC3). By comparison with $\mathrm{TC} 0$, this gives access to the radial temperature gradient.

\section{Numerical Modelling of Gleeble Tension Tests}

\subsection{Geometrical Model}

In the numerical simulation of Gleeble tension tests, both the specimen and copper grips are taken into account and assumed as axi-symmetric, without considering the nuts at both ends of the specimen, as shown in Figure 3. The free surfaces and contact interfaces that will be mentioned in the following paragraphs are also indicated. The boundaries $\partial \Omega_{\mathrm{gf1}}$ and $\partial \Omega_{\mathrm{gf} 2}$ are the two lateral surfaces of the grips in contact with the Gleeble framework. $\partial \Omega_{\mathrm{sg}}$ is the contact interface between the grips and the specimen. The boundary $\partial \Omega_{\mathrm{s}}$ is the surface of the specimen which is between the two grips. Finally, the boundaries $\partial \Omega_{\mathrm{g}_{\_} \text {es }}$ and $\partial \Omega_{\mathrm{g}_{-} \text {is }}$ are the outer and inner side surfaces of the grips, respectively.

\subsection{Electrical Solution}

The electrical potential field in a conductor is governed by Maxwell's equation of conservation of electrical charge. When assuming steady-state direct current (DC), the equations can be written as follows ${ }^{[13]}$ :

$$
\begin{gathered}
\mathbf{J}=-\sigma_{\text {elec }} \nabla \phi \\
\nabla \cdot \mathbf{J}=0
\end{gathered}
$$

where $\phi$ is the electrical potential, $\sigma_{\text {elec }}$ is the electrical conductivity, and $\mathbf{J}$ is the electrical current density vector. The solution of the electrical problem consists then in solving the following Poisson type equation for the electrical potential:

$$
\nabla \cdot\left(\sigma_{\text {elec }} \nabla \phi\right)=0
$$

Three types of boundary conditions may be used: 


$$
\begin{gathered}
\phi=\phi_{\text {imp }} \\
-\mathbf{J} \cdot \mathbf{n}=J_{\text {imp }} \\
-\mathbf{J} \cdot \mathbf{n}=h_{\text {elec }}\left(\phi-\phi_{\text {contact }}\right)
\end{gathered}
$$

Eq. 4a stands for a prescribed electrical potential $\phi_{\mathrm{imp}}$ at boundary. This boundary condition is used on the surface $\partial \Omega_{\mathrm{gf} 2}$ of the fixed grip with $\phi_{\mathrm{imp}}=0$.

Eq. $4 \mathrm{~b}$ corresponds to the imposition of an electrical current density $J_{\text {imp }}$, with $\mathbf{n}$ denoting the local outward unit normal vector. This boundary condition is used on the surface $\partial \Omega_{\mathrm{gfl}}$ of the mobile grip, the value of $J_{\text {imp }}$ being possibly automatically calculated and dynamically updated to control the specimen temperature, as explained further.

Eq. 4c expresses a non-perfect electrical contact: the input electrical current density is then related to the local difference of electrical potential. $\phi_{\text {contact }}$ is the local electrical potential at the surface of the neighbor domain and $h_{\text {elec }}$ is an effective electrical transfer coefficient. This condition is used along the interface $\partial \Omega_{\mathrm{sg}}$ between the specimen and the grips. In the case of a quasi perfect electrical contact, an arbitrary large value for $h_{\text {elec }}$ is used, resulting in a very small difference between the electrical potentials, expressing the quasi continuity of $\phi$ through the interface.

Using Green's (divergence) theorem, the weak or global form of Eq. 3 is:

$$
\forall \phi^{*}, \quad \int_{\Omega} \sigma_{\text {elec }} \nabla \phi \cdot \nabla \phi^{*} \mathrm{~d} \Omega+\int_{\partial \Omega} \phi^{*} \mathbf{J} \cdot \mathbf{n} \mathrm{d} \Gamma=0
$$

where $\phi^{*}$ denotes scalar test functions and $\partial \Omega$ denotes the surface of the specimen, which can be decomposed as indicated in Figure 3, with boundary conditions specified in Eq. 4. A classical Galerkin finite element formulation is used to discretize this equation, leading to a set of linear equations to be solved for the nodal values of the electrical potential. A multi-domain resolution strategy is used to solve the electrical potential in the grips and the specimen, with details expanded in section 3.5.

\subsection{Energy Equation Resolution}

Considering Joule heat input, but neglecting the heat source associated with deformation power (as only very low strain-rates are envisaged here), the energy conservation writes ${ }^{[13]}$ : 


$$
\rho \frac{\mathrm{d} h}{\mathrm{~d} t}-\nabla \cdot(\lambda \nabla T)=P_{\mathrm{v}}^{\mathrm{elec}}
$$

where $\rho$ denotes the density, $h$ the specific enthalpy, $\lambda$ the heat conductivity, $T$ the temperature. The specific enthalpy $h$ is defined as:

$$
h=\int_{T_{\text {ref }}}^{T} c_{\mathrm{p}}(\tau) d \tau+f_{1} L
$$

with $T_{\text {ref }}$ an arbitrary reference temperature, $c_{\mathrm{p}}$ the specific heat, $f_{1}$ the mass fraction of liquid and $L$ the specific latent heat of fusion. In the present study, mass and volume fractions will be assumed identical and given as a function of temperature. Therefore, the value of the specific enthalpy can be calculated for any value of the temperature.

In Eq. 6, $P_{\mathrm{v}}^{\text {elec }}$ is the volume heat source associated with resistance heating, which is given by Joule's law ${ }^{[13]}$ :

$$
P_{\mathrm{v}}^{\mathrm{elec}}=\sigma_{\mathrm{elec}}^{-1} \mathbf{J} \cdot \mathbf{J}=\sigma_{\text {elec }} \nabla \phi \cdot \nabla \phi
$$

Three types of thermal boundary conditions may be used:

$$
\begin{gathered}
-\lambda \nabla T \cdot \mathbf{n}=q_{\text {imp }} \\
-\lambda \nabla T \cdot \mathbf{n}=h_{\mathrm{c}}\left(T-T_{\text {contact }}\right)+\frac{b}{b+b_{\text {contact }}} P_{\text {interface }}^{\text {elec }} \\
-\lambda \nabla T \cdot \mathbf{n}=h_{\text {th_eff }}\left(T-T_{\text {env }}\right)
\end{gathered}
$$

where

$$
b=\sqrt{\lambda \rho c_{\mathrm{p}}} \text { and } \quad P_{\text {interface }}^{\text {elec }}=h_{\text {elec }}\left(\phi-\phi_{\text {contact }}\right)^{2}
$$

Eq. 9a means a prescribed heat flux. Such a condition is applied to the inner and outer side surfaces of grips $\partial \Omega_{\mathrm{g}_{-} \text {es }}$ and $\partial \Omega_{\mathrm{g}_{-}}$is, and to the end surface of specimen $\partial \Omega_{\mathrm{s}_{-} \text {es }}$, with $q_{\text {imp }}=0$ for both cases, expressing assumed adiabatic boundary conditions.

Eq. $9 \mathrm{~b}$ represents the non-perfect thermal contact condition at the interface between specimen and grips $\partial \Omega_{\mathrm{sg}}$. $T_{\text {contact }}$ is the local temperature at the surface of the neighbor domain and $h_{\mathrm{c}}$ is an effective heat transfer coefficient defined at the interface between specimen and grips. The Joule heat power is distributed between the two domains in contact according to their respective thermal effusivities $b$. 
Due to the complex heat transfer conditions between the specimen, the transparent quartz tube and the environment, an equivalent heat transfer model (Eq. 9c) between the specimen and the environment is assumed by defining an effective heat transfer coefficient $h_{\text {th_eff, }}$ which will be determined by an inverse numerical calculation based on the experimental temperature measurements. This point is discussed later on, in Section 4.2.

Multi-domain resolution strategy is used, which is detailed in section 3.5. It should be noted that when computing the solution in one of the grips, the heat transfer model of Eq. 9c is also used at the surface $\left(\partial \Omega_{\mathrm{gf} 1}\right.$ or $\left.\partial \Omega_{\mathrm{gf} 2}\right)$ in contact with the framework.

The weak form of Eq. 6 is:

$$
\forall \varphi^{*}, \quad \int_{\Omega} \rho \frac{\mathrm{d} h}{\mathrm{~d} t} \varphi^{*} d \Omega+\int_{\Omega} \lambda \nabla T \cdot \nabla \varphi^{*} d \Omega+\int_{\partial \Omega}-\lambda \nabla T \cdot \mathbf{n} \varphi^{*} d \Gamma-\int_{\Omega} P_{\mathrm{v}}^{\mathrm{elec}} \varphi^{*} d \Omega=0
$$

where $\varphi^{*}$ are scalar test functions. Like for the electrical solution, a classical Galerkin finite element formulation is used to discretize this equation. This leads to a set of non-linear equations to be solved for the nodal values of specific enthalpy. This set is linearized by means of an implicit formulation and a Newton-Raphson method, for which the tangent stiffness matrix involves the nodal values of $\partial T / \partial h$. When the energy equation is solved in grips, temperature $T$ is chosen as the primary unknown and the weak form (Eq. 10) can be reduced to:

$$
\forall \varphi^{*}, \quad \int_{\Omega} \rho c_{\mathrm{p}} \frac{\mathrm{d} T}{\mathrm{~d} t} \varphi^{*} d \Omega+\int_{\Omega} \lambda \nabla T \cdot \nabla \varphi^{*} d \Omega+\int_{\partial \Omega}-\lambda \nabla T \cdot \mathbf{n} \varphi^{*} d \Gamma-\int_{\Omega} P_{\mathrm{v}}^{\mathrm{elec}} \varphi^{*} d \Omega=0
$$

In this case, taking the values of $\rho, \lambda$ and $c_{\mathrm{p}}$ - which generally depend on $T-$ at the beginning of the time step, we get a set of linear equations to be solved for the nodal temperatures.

\subsection{Mechanical Momentum Equation Resolution}

The constitutive models that are to be considered in the present study should cover the solid state and the mushy state, which can be present at the same time in a tensile specimen. This is why we use the hybrid approach developed by Bellet et al. for the modelling of solidification processes ${ }^{[14,15]}$. This approach is briefly summarized hereafter.

In the mushy state, a pure thermo-viscoplastic (THVP) law is used above solidus temperature and 
described by the following equations:

$$
\begin{aligned}
\dot{\boldsymbol{\varepsilon}} & =\dot{\boldsymbol{\varepsilon}}^{\mathrm{vp}}+\dot{\boldsymbol{\varepsilon}}^{\text {th }} \\
\dot{\boldsymbol{\varepsilon}}^{\mathrm{vp}} & =\frac{3}{2 K_{\mathrm{vp}}} \dot{\bar{\varepsilon}}^{1-m} \mathbf{S} \\
\dot{\boldsymbol{\varepsilon}}^{\text {th }} & =-\frac{1}{3 \rho} \frac{d \rho}{d t} \mathbf{I}
\end{aligned}
$$

The strain-rate tensor is decomposed into a viscoplastic and a thermal part, as indicated by Eq. 12a: no elasticity is considered. In Eq. 12c, the change of the material density $\rho$ expresses the shrinkage term associated with the liquid-solid phase change. I denotes the identity tensor. Eq. $12 \mathrm{~b}$ is the classical constitutive equation of a generalized non-Newtonian fluid. $K_{\mathrm{vp}}$ is the so-called viscoplastic consistency of the material, $m$ is the strain rate sensitivity coefficient and $\mathbf{s}$ is the deviatoric stress tensor as deduced from the Cauchy stress tensor $\boldsymbol{\sigma}$ :

$$
\mathbf{s}=\boldsymbol{\sigma}-\frac{1}{3} \operatorname{tr}(\boldsymbol{\sigma}) \mathbf{I}
$$

Denoting $\dot{\bar{\varepsilon}}$ and $\bar{\sigma}$ the von Mises equivalent strain rate and equivalent stress, respectively defined by:

$$
\dot{\bar{\varepsilon}}=\sqrt{\frac{2}{3} \dot{\varepsilon}_{i j}^{\mathrm{vp}} \dot{\varepsilon}_{i j}^{\mathrm{vp}}}, \quad \bar{\sigma}=\sqrt{\frac{3}{2} s_{i j} s_{i j}}
$$

From Eq. $12 \mathrm{~b}$ and Eq. 14, the one-dimensional power-law type relationship between stress and strain-rate invariants can be achieved:

$$
\bar{\sigma}=K_{\mathrm{vp}} \dot{\bar{\varepsilon}}^{m}
$$

Below the solidus temperature, the alloy is modeled by a thermo-elastic-viscoplastic (THEVP) constitutive law, which is more representative of solid-like behavior. The solid-like constitutive equations are described by the following equations, in which small deformations and rotations are assumed, which is consistent with our application field.

$$
\begin{gathered}
\dot{\boldsymbol{\varepsilon}}=\dot{\boldsymbol{\varepsilon}}^{\mathrm{el}}+\dot{\boldsymbol{\varepsilon}}^{\mathrm{vp}}+\dot{\boldsymbol{\varepsilon}}^{\mathrm{th}} \\
\dot{\boldsymbol{\varepsilon}}^{\mathrm{el}}=\frac{1+v}{E} \dot{\boldsymbol{\sigma}}-\frac{v}{E} \operatorname{tr}(\boldsymbol{\sigma}) \mathbf{I} \\
\dot{\boldsymbol{\varepsilon}}^{\mathrm{vp}}=\frac{3 \overline{\bar{\varepsilon}}}{2 \bar{\sigma}} \mathbf{S}
\end{gathered}
$$


The strain rate tensor $\dot{\boldsymbol{\varepsilon}}$ is split into an elastic component, an inelastic (non reversible) component, and a thermal component. Here $E$ and $v$ are the notations for Young's modulus and Poisson's ratio.

Different constitutive equations can be introduced to describe the relation between the von Mises equivalent strain rate and stress. In the present work, the following constitutive equation is chosen, in which strain hardening and strain rate sensitivity effects are taken into account by an additive formulation ${ }^{[16]}$.

$$
\bar{\sigma}=\sigma_{\mathrm{y}}+H_{\mathrm{evp}} \bar{\varepsilon}^{n}+K_{\mathrm{evp}} \dot{\bar{\varepsilon}}^{m}
$$

In this expression, $\sigma_{\mathrm{y}}$ denotes the initial yield stress. The current yield stress is assumed to depend on the cumulated plastic strain, its value being $\sigma_{\mathrm{y}}+H_{\mathrm{evp}} \bar{\varepsilon}^{n}$, due to strain hardening. Strain rate sensitivity is taken into account through a power law of coefficients $K_{\text {evp }}$ and $m$. In this case, Eq. $16 \mathrm{c}$ takes the form:

$$
\dot{\boldsymbol{\varepsilon}}^{\mathrm{vp}}=\frac{3}{2 \bar{\sigma}}\left\langle\frac{\bar{\sigma}-\left(\sigma_{\mathrm{y}}+H_{\mathrm{evp}} \bar{\varepsilon}^{n}\right)}{K_{\mathrm{evp}}}\right\rangle^{1 / m} \mathbf{s}
$$

The expression between Macauley brackets $\langle\bullet\rangle$ is reduced to zero when negative, expressing plastic yield.

The local mechanical equilibrium is governed by the momentum conservation equation, in which, regarding the low velocities in such Gleeble tests, inertia effects are ignored ${ }^{[13]}$ :

$$
\nabla \cdot \boldsymbol{\sigma}+\rho \mathbf{g}=0
$$

Regarding mechanical boundary conditions, the grips are assumed non deformable. One grip is fixed while the mobile grip has a prescribed time-dependent velocity $V_{\text {imp }}(t)$. The specimen undergoes mechanical boundary conditions at the interface with grips $\partial \Omega_{\mathrm{sg}}$ only. In the present study, as it will be discussed later on (Section 4.3), two kinds of contact conditions are addressed at this interface: bilateral sticking contact and bilateral sliding contact without friction. Denoting $\mathbf{v}$ and $\mathbf{v}_{\mathrm{g}}$ the velocity fields in the specimen and in the grips respectively, the bilateral sticking condition can be expressed by:

$$
\begin{gathered}
\mathbf{v}-\mathbf{v}_{\mathrm{g}}=0 \\
\mathbf{T}=\boldsymbol{\sigma} \mathbf{n}=-\chi_{\mathbf{p}}\left(\mathbf{v}-\mathbf{v}_{\mathrm{g}}\right)
\end{gathered}
$$

The fulfillment of Eq. 20 is obtained by means of a penalty method, which consists in applying a 
stress vector $\mathbf{T}$ (Eq. 21) to the surface of the specimen, with $\chi_{\mathrm{p}}$ denoting the penalty coefficient (a large positive number).

The bilateral frictionless sliding condition can be expressed by:

$$
\begin{gathered}
\left(\mathbf{v}-\mathbf{v}_{\mathrm{g}}\right) \cdot \mathbf{n}=0 \\
\mathbf{T}=\boldsymbol{\sigma} \mathbf{n}=-\chi_{\mathrm{p}}\left(\left(\mathbf{v}-\mathbf{v}_{\mathrm{g}}\right) \cdot \mathbf{n}\right) \mathbf{n}
\end{gathered}
$$

The mechanical problem is solved using a mixed formulation with velocity and pressure as primitive variables. The problem to be solved is then composed of two equations. The first one is the weak form of the momentum equation, also known as the principle of virtual power. Since $p$ is kept as a primitive variable, only the deviatoric part of constitutive equations is accounted for and has to be solved locally in order to determine the deviatoric stress tensor $\mathbf{s}$. Therefore the second equation consists of the weak form of the volumetric part of the constitutive equations. It expresses the incompressibility of the plastic deformation. This leads to ${ }^{[17,18]}$.

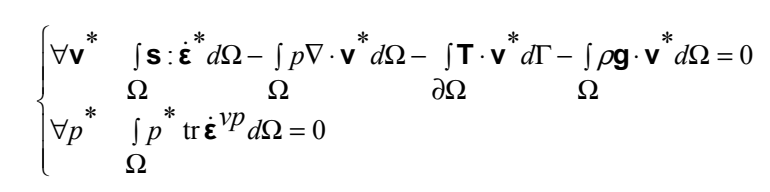

where $v^{*}$ and $p^{*}$ are respectively a vector and a scalar test functions which can be seen as virtual velocity and pressure fields.

The form of the term integrated in the second equation varies according to the local state of steel (i.e. solid or mushy). In the case of a solid-like constitutive equation (solid state, elastic-viscoplastic behaviour), it is:

$$
\operatorname{tr} \dot{\boldsymbol{\varepsilon}}^{\mathrm{vp}}=\operatorname{tr} \dot{\boldsymbol{\varepsilon}}-\operatorname{tr} \dot{\boldsymbol{\varepsilon}}^{\mathrm{el}}-\operatorname{tr} \dot{\boldsymbol{\varepsilon}}^{\text {th }}=\nabla \cdot \mathbf{v}+\frac{3(1-2 v)}{E} \dot{p}-\frac{1}{\rho} \frac{d \rho}{d t}=0
$$

In the case of a liquid-like constitutive equation (mushy state, pure viscoplastic behaviour), it is:

$$
\operatorname{tr} \dot{\boldsymbol{\varepsilon}}^{\mathrm{vp}}=\operatorname{tr} \dot{\boldsymbol{\varepsilon}}-\operatorname{tr} \dot{\boldsymbol{\varepsilon}}^{\text {th }}=\nabla \cdot \mathbf{v}-\frac{1}{\rho} \frac{d \rho}{d t}=0
$$

Accordingly, the stress deviator $\mathbf{s}$ is deduced either from a viscoplastic law, or from an elastic-viscoplastic constitutive equation. In the first case, $\mathbf{s}$ can be easily deduced from Eq. 12, from which we get: 


$$
\mathbf{S}=\frac{2}{3} K_{\mathrm{vp}} \dot{\bar{\varepsilon}}^{m-1} \operatorname{dev}(\dot{\boldsymbol{\varepsilon}})
$$

In the second case (elastic-viscoplastic behaviour), the resolution of Eq. 26 consists in solving a non-linear scalar equation. This can be achieved by means of a Newton method ${ }^{[19]}$.

After spatial discretization with the triangular mini-element $(\mathrm{P} 1+/ \mathrm{P} 1)$, for which details can be found in literature [20], Eq. 23 can be cast in a set of non linear equations the unknowns of which are the nodal velocities and pressure. This system is solved by a Newton-Raphson method.

\subsection{Finite Element Discretization and Multi-Domain Multi-Field Coupling Resolution Strategy}

The specimen and two grips are spatially discretized on linear triangle elements, which can be shown in Figure 4. To capture the thermal and mechanical gradients in the working zone of the specimen, a fine mesh is generated in this region with mesh size about $0.2 \mathrm{~mm}$.

The electrical, thermal and mechanical equations (Eq. 5, 10 and 23) are solved by the two-dimensional axisymmetric finite element code R2SOL-CA developed at CEMEF. Within each time increment, the converged consistent resolutions of electrical, energy and momentum conservation equations can be achieved through multi-field coupling iterations, as is shown in Figure 5a. At each coupled iteration, the electrical and the energy equation must be solved in all the domains, which are the specimen and two grips in the present context. Local converged resolutions of each physical field are achieved by inner iterations between domains, as is shown in Figure 5b. In the present study, because there is no severe coupling relationship between electrical, thermal and mechanical variables, a weak coupling resolution strategy can be used in practice, rather than the full coupling resolution method indicated in Figure 5a. This saves computational time and it has been checked that this does not affect the accuracy of the solution.

\section{Results and Discussion}

The electrical, thermal and mechanical properties of the considered UHS steel, which are used in the present numerical modelling of Gleeble tests, are listed in the Appendix. 


\subsection{Electrical Simulation Analysis}

As shown in Figure 2, the specimen is heated by the electrical current, according to the prescribed heating history. Regarding boundary conditions, the electrical transfer coefficient along the interface with grips, $h_{\text {elec, }}$, is unknown. This coefficient may affect the potential distribution. It may also affect the temperature distribution, especially the axial profile, together with the heat transfer coefficient along the same interface: $h_{\mathrm{c}}$. Therefore, both coefficients should be identified. Moreover, due to the smooth and tight contact condition between grips and specimen, it can be thought that the two transfer coefficients take high values, leading to quasi continuous profiles of electrical potential and temperature through the interface. In order to simplify the numerical determination procedure, an arbitrary high value is chosen for the electrical transfer coefficient: $h_{\text {elec }}=3 \times 10^{8} \Omega^{-1} \mathrm{~m}^{-2}$. Thus, only the heat transfer coefficient $h_{\mathrm{c}}$ has to be determined by a numerical inverse determination procedure based on temperature measurements. It will be shown in Section 4.2 that this strategy leads to a good agreement between measured and calculated temperatures.

Zero potential is imposed on the surface $\partial \Omega_{\mathrm{gf} 2}$, and the electrical current density $J_{\text {imp }}$ is imposed on $\partial \Omega_{\mathrm{gfl}}$. The value of $J_{\mathrm{imp}}$ is regulated by a simple PID (proportional-integral-derivative) algorithm to control the heating rate of the specimen according to the prescribed heating history. At each time increment, the incremental correction for $J_{\text {imp }}$ is calculated as a function of the errors between the calculated and prescribed temperatures ${ }^{[21]}$ :

$$
\Delta J_{\mathrm{imp}}=k_{\mathrm{p}} e^{t}+k_{\mathrm{i}} \sum_{t=0}^{t} e^{t}+k_{\mathrm{d}}\left(e^{t}-e^{t-1}\right)
$$

where $k_{\mathrm{p}}, k_{\mathrm{i}}$ and $k_{\mathrm{d}}$ are proportional, integral and derivative constants. $t$ represents the time indicator and $e^{t}$ is expressed as:

$$
e^{t}=T_{\mathrm{obj}}^{t}-T_{\mathrm{cal}}^{t}
$$

The imposed $J_{\text {imp }}$ is then updated by:

$$
J_{\text {imp }}^{t}=J_{\text {imp }}^{t-1}+\Delta J_{\text {imp }}
$$

The electrical potential distribution and the electrical current density distribution are shown in Figure 6. Basically the electrical potential gradient reaches its maximum value in the middle part of the specimen. Consequently, the electrical current density reaches its maximal value at the same location. It 
can be seen in Figure $6 \mathrm{~b}$ that the current density is found almost uniform in the middle part of the specimen, on a length of approximately $28 \mathrm{~mm}$, and decreases to zero at both ends of the specimen. This characteristic distribution of electrical current explains the rapid and effective heating of most of the working zone (34 $\mathrm{mm}$ between grips) of the specimen, but also the axial temperature gradients prevailing in this zone. This is to be discussed in the next Section.

\subsection{Thermal Simulation Analysis}

The non steady state heat transfer is modelled in the whole set-up, including grips. Before discussing the boundary conditions, the transient temperature control of the specimen is presented first. As explained above, a PID numerical algorithm is used to regulate the prescribed electrical current in order to minimize the difference between the calculated and the aimed nominal temperature at the location of the thermocouple TC 0 in Figure 1b. As shown by the temperature curves in Figure 7 and as expected, the history of the calculated temperature at this position reproduces exactly the desired heating path. A similar control is obtained experimentally through the monitoring procedure of the Gleeble machine. Both monitoring procedures (experimental and numerical) are then satisfying and consistent, allowing the operator and the code user to get the prescribed temperature evolution curve.

The framework of the Gleeble machine is water-cooled. Regarding the grips, the strong heat transfer between copper grips and steel framework is taken into account by setting the local heat transfer coefficient $h_{\text {th_eff }}=2000 \mathrm{~W} \mathrm{~m}^{-2} \mathrm{~K}^{-1}$ (Eq. 9c) along interfaces $\partial \Omega_{\mathrm{gfl}}$ and $\partial \Omega_{\mathrm{gf2}}$. The heat transfer coefficient $h_{\mathrm{c}}$ along the interfaces between grip and specimen are inversely determined based on the surface temperature measurements along axis, which is detailed in the following paragraphs.

Regarding the specimen, the temperature difference between surface and core, that is the radial gradient, is mainly affected by $h_{\text {th_eff }}($ Eq. 9 c). This heat transfer coefficient is determined after the temperature of the specimen has been stabilized (between 70 and 130 s, see Figure 7). A numerical inverse method is used that decreases the error between the calculated and measured surface temperature $\left(T_{\mathrm{s}}\right.$, measured at position $\left.\mathrm{TC} 0\right)$ and core temperature $\left(T_{\mathrm{c}}\right.$, measured at position $\left.\mathrm{TC} 3\right)$. Figure 8 shows the temperature difference $\left(T_{\mathrm{c}}-T_{\mathrm{S}}\right)$ between the core $\left(T_{\mathrm{c}}\right)$ and the surface temperature $\left(T_{\mathrm{s}}\right)$ vs the surface temperature. It can be seen that, as expected, the radial temperature gradient increases significantly with the surface temperature of the specimen. For temperatures as high as the 
solidus temperature of the UHS steel $\left(1437^{\circ} \mathrm{C}\right)$, it can be anticipated by extrapolation of these results that the temperature difference between core and surface should reach 70 to $80{ }^{\circ} \mathrm{C}$.

Let us now consider the axial thermal gradient taking place in the specimen. The quasi uniform profile of electrical current density in most of the working zone (Figure 6b) ensures that the Joule heat source term is uniformly distributed in this region. However, thermal axial diffusion towards the cooler grips gives birth to an axial temperature gradient in the working zone. The heat transfer coefficient along the grip/specimen interfaces $h_{\mathrm{c}}$ is determined by decreasing the difference between the calculated and measured temperature profiles along the surface of the specimen, during the homogenization period (from 70 to $130 \mathrm{~s}$ ). Figure 9a shows a comparison between calculated and measured longitudinal temperature profiles along the surface of the specimen in its central region (up to $12 \mathrm{~mm}$ from the mid-length transverse section, in the region of the three thermocouples TC0, TC1 and TC2). This comparison is given for three controlled temperatures for the central thermocouple TC0: 1200, 1300 and $1400{ }^{\circ} \mathrm{C}$. Thanks to the numerical PID monitoring of the calculated temperature in the numerical simulation (as well as for the TC0 temperature in the experiment), there is a perfect agreement between simulation and experiment for this position. Figure 9a shows also a good agreement at the two locations TC1 and TC2.

Although the vacuum chamber and quartz tube are used in the tests, there exist surface heat losses from the free surface of the specimen between grips. The radial thermal gradients are increased with the increasing surface temperature (TC0 location), which can be clearly seen on the simulation results in Figure $9 \mathrm{~b}$. On this figure, it can also be seen that the identification of coefficient $h_{\text {th_eff }}$ yields core temperatures in excellent agreement with the measurements already reported in Figure 8.

The previous results are quite interesting because they show that despite the rather extended (30 $\mathrm{mm}$ ) central zone with quite homogeneous electrical current density (Figure 6b), there is actually no real homogeneity of temperature in the working zone, neither in the axial nor in the radial directions. It should also be noted that the different distributions also depend on the material parameters themselves, especially the temperature dependence of the electrical conductivity.

Because of the existence of these thermal gradients, fusion of steel and then a mushy zone will first appear in the central core zone of the specimen when the nominal surface temperature increases and exceeds a certain value. Figure 10a shows the calculated temperature distribution with surface 
temperature $1400{ }^{\circ} \mathrm{C}$. Axial and radial temperature gradients result in a central ellipsoidal mushy zone, the surface of which is determined by the iso-temperature surface $\mathrm{T}=1437^{\circ} \mathrm{C}$ (solidus temperature of the UHS steel). The axial extension of the calculated mushy zone is about $11 \mathrm{~mm}$, while its radial extension is about $7.5 \mathrm{~mm}$. Inside the mushy zone, thermal gradients are associated with liquid fraction gradients as is shown in Figure 10b (maximum liquid fraction in this case: 0.22 ).

\subsection{Mechanical Simulation Analysis}

During the heating stage for real specimens, if the grips are kept fixed, dilatation effects (Eq. 12c) lead to substantial compressive stresses in the material, which may cause damage. This is why in real Gleeble tests, a so-called "zero force" technique is used for grip adjustment in order to reduce thermal stresses, which means that the movable grip can freely move to reduce the detected force under a small tolerance force (near zero). During the present numerical simulation, in order to model this "zero force" control, a boundary condition switch technique has been developed, using bilateral frictionless sliding before starting mechanical tension, and then bilateral sticking during mechanical tension. As shown in Figure 7, after heating and temperature homogeneization, at time $320 \mathrm{~s}$, just before loading, the numerical simulation shows that the specimen has extended by $0.9 \mathrm{~mm}$ axially (that is $0.75 \%$ of total length) and $0.09 \mathrm{~mm}$ radially ( $1.8 \%$ of the radius in the working zone). Although the moving grip is left free during the heating stage, the numerical simulation reveals that there is a substantial thermal stress due to the radial constraint exerted by grips in the grip holding region, as shown in Figure 11, for a nominal temperature of $1300{ }^{\circ} \mathrm{C}$. However, it should be noticed that such a stress state is probably overestimated because the grips being assumed rigid in the simulation, dilatation effects are not taken into account in the grips themselves. Despite this rough approximation, it can be noted that actually small thermal stress is observed in the central part of the specimen $(<1 \mathrm{MPa})$.

As expected, the non-uniform temperature distribution in the specimen gives birth to strong deformation heterogeneity. This is evidenced by Figure 12a: the calculated strain rate in the specimen is actually far from being uniform. Because of axial and radial temperature gradients, there is a strain concentration in the vicinity of the core center of the specimen, where the equivalent strain rate $\dot{\bar{\varepsilon}}$ reaches a maximum of $1.2 \times 10^{-3} \mathrm{~s}^{-1}$ for a nominal temperature of $1200{ }^{\circ} \mathrm{C}$ and a constant velocity $V_{\text {imp }}=$ $0.01 \mathrm{~mm} / \mathrm{s}$ of the moving grip. The effective working zone (in which material deforms) is about $20 \mathrm{~mm}$ 
long in the central part. It can be noted that during tension, this effective working zone is enlarged to 25 $\mathrm{mm}$ (see Figure 12a), yielding a lower maximum strain rate of $0.8 \times 10^{-3} \mathrm{~s}^{-1}$. Besides, the radial heterogeneity of the deformation can be clearly seen in Figure $12 \mathrm{~b}$.

\section{Influence of the constitutive equation}

It is interesting to realize that such deformation heterogeneities are highly dependent on the constitutive model chosen for the alloy. As a demonstration, let us consider an alternative equation to Eq. 17, provided by Han et al. ${ }^{[22]}$ :

$$
\bar{\sigma}=\frac{\bar{\varepsilon}^{n}}{\alpha} \operatorname{arsinh}\left[\left(\frac{1}{A} \exp \left(\frac{Q}{R T}\right)\right)^{m} \dot{\bar{\varepsilon}}^{m}\right]
$$

The corresponding material parameters for the considered UHS steel are taken from Seol et al. ${ }^{[8]}$ and can be found in the Appendix (Table 2).

Using this model, the strain-rate distribution is quite different, as shown in Figure 13. It can be seen that in contrast to the previous model, the strain-rate concentration is lower: the maximum strain-rate in the beginning of the test is limited to $0.85 \times 10^{-3} \mathrm{~s}^{-1}$ instead of $1.16 \times 10^{-3} \mathrm{~s}^{-1}$. The effective working zone is slightly larger in the beginning of the test and it does not vary during the test, contrary to the previous case. In addition, during the test, a slight increase of the maximum strain-rate is now observed, instead of a larger decrease using the additive model. These different evolutions are illustrated in Figure 14.

As classified by Lemaitre and Chaboche ${ }^{[16]}$, the effects of strain hardening and strain rate hardening can be combined by two ways in viscoplastic constitutive models: additive and multiplicative, which can be simply written into the following two equation types:

$$
\begin{aligned}
& \text { Additive: } \bar{\sigma}=H_{\mathrm{evp}} \bar{\varepsilon}^{n}+K_{\mathrm{evp}} \dot{\bar{\varepsilon}}^{m} \text { or } \dot{\bar{\varepsilon}}=\left(\left(\bar{\sigma}-H_{\mathrm{evp}} \bar{\varepsilon}^{n}\right) / K_{\mathrm{evp}}\right)^{1 / m} \\
& \text { Multiplicative: } \bar{\sigma}=K_{\mathrm{evp}} \bar{\varepsilon}^{n} \dot{\bar{\varepsilon}}^{m} \text { or } \dot{\bar{\varepsilon}}=\left(\bar{\sigma} /\left(K_{\mathrm{evp}} \bar{\varepsilon}^{n}\right)\right)^{1 / m}
\end{aligned}
$$

It can be thought that the second form, in which the term $\bar{\varepsilon}^{n}$ is found in the numerator, promotes the influence of the strain-hardening effect, leading to lower strain-rate concentrations. This seems to be consistent with Figure 12 and Figure 13. 


\section{About forthcoming parameters identification}

From the different thermal and mechanical results shown previously, it can be anticipated that the identification of material behaviour at high temperature in the solid state, and a fortiori in the mushy state, is really challenging. The only way through it probably consists in inverse numerical modelling based on measurement of traction force and displacement. Success in this matter will rely on three essential requirements: i) reliable direct numerical simulation and inverse optimization module ii) accurate temperature measurements and iii) good knowledge of thermophysical properties of the material.

Inverse identification would consist in finding the set of material parameters minimizing the difference between measured and calculated force-elongation curves for a set of tensile tests performed in different conditions (traction velocity, temperature). As already mentioned, in the present numerical model, traction velocity is directly prescribed, and the nominal temperature is well controlled, like in real tests. Regarding elongation, it is directly obtained in the simulation by the following integration:

$$
\Delta l(t)=\int_{t_{\mathrm{ms}}}^{t} V_{\mathrm{imp}}(\tau) \mathrm{d} \tau
$$

where $t_{\mathrm{ms}}$ denotes the time at which tension is started and $V_{\mathrm{imp}}$ is the velocity that is imposed on the movable grip. As for the tensile force, its calculation is more delicate. In our finite element approach, it is calculated by two methods. The first one consists in summing all contact nodal forces associated with the penalty treatment of sticking contact:

$$
F(t)=\sum_{\text {contact nodes } n} \mathbf{T}_{n}(t) \cdot \mathbf{e}_{z} 2 \pi r_{n} l_{n}
$$

where the nodal stress vector (surface force) is calculated by Eq. 21, $\mathbf{e}_{\mathrm{z}}$ denotes the unit vector along the axial direction, $r_{n}$ and $l_{n}$ are respectively the radial coordinate and the control length associated with any boundary node $n$. In the second method, the force is deduced from the distribution of axial stress components along the central transverse section of the specimen:

$$
F(t)=\sum_{e} \sigma_{z z}(e) 2 \pi r_{e} \Delta r_{e}
$$

where the summation is applied to the triangular elements $e$ crossed by the central tranverse section, 
$\sigma_{\mathrm{zz}}(e)$ is the axial stress component calculated at the center of element $e, r_{e}$ is the radial coordinate of the center of element $e$, and $\Delta r_{\mathrm{e}}$ is the dimension of element $e$ along the radial direction. It has been checked that the two methods lead to extremely close values of $F$.

Figure 15 shows the calculated curves, traction force vs elongation, for three different temperatures and a constant grip velocity $0.01 \mathrm{~mm} / \mathrm{s}$, using the additive constitutive model. Temperature and strain hardening effects are clearly evidenced. Large differences are recorded between measured and calculated curves, illustrating the need of a complementary identification of constitutive parameters through a procedure based upon inverse finite element analysis.

\section{Conclusion}

Through this study, a coupled electrical-thermal-mechanical model has been proposed and discussed for the direct numerical modelling of Gleeble tests at high temperature and in the mushy state. Direct modelling of Gleeble tension tests for a UHS steel has revealed that thermal gradients arising from the coupled electrical-thermal problem significantly affect the material and result in turn in a heterogeneous deformation of the specimen. This point constitutes a major difficulty for a simple identification of constitutive parameters, using direct estimations of strain, strain rate and stress. Given such marked heterogeneities, the only safe procedure appears to be inverse numerical modelling based on direct coupled finite element models, such as the one presented here. Identification should then be performed by an optimization module aiming at the minimization of the difference between force-displacement curves (or the possible specimen shape difference between calculations and measurements) for a set of tests achieved under different conditions (temperature and imposed velocity). Success in this matter will definitely require: i) a reliable direct coupled numerical simulation, ii) a robust and efficient optimization module, iii) accurate temperature measurements during real tests and iv) a good knowledge of thermophysical properties of the material.

\section{Acknowledgements}

This study has been financially supported by the company ArcelorMittal, which supported a two-year period passed by Changli Zhang in CEMEF laboratory. 


\section{Appendix: Material Properties of the UHS Steel}

To calculate the solidification path of the considered UHS steel, the microsegregation model presented by Won et al. ${ }^{[23]}$ is used here, which takes into account the steel composition and cooling rate. The model is briefly listed here:

$$
\begin{gathered}
f_{\mathrm{s}}=\left(\frac{1}{1-2 \beta k}\right)\left[1-\left(\frac{T_{\mathrm{f}}-T}{T_{\mathrm{f}}-T_{\mathrm{L}}}\right)^{(1-2 \beta k) /(k-1)}\right] \\
\beta=a\left[1-\exp \left(\frac{-1}{a}\right)\right]-\frac{1}{2} \exp \left[\frac{-1}{2 a}\right] \\
a=33.7 \dot{T}^{-0.244}
\end{gathered}
$$

where $k$ is the equilibrium partition coefficient of carbon (taken as 0.265 ), $T_{f}$ is the melting temperature of pure $\mathrm{Fe}$ (taken as $1535^{\circ} \mathrm{C}$ ). The liquidus temperature can be determined by

$$
T_{\mathrm{L}}=1535-78(w t \% C)-7.6(w t \% S i)-4.9(w t \% M n)-34.4(w t \% P)-38(w t \% S)
$$

where temperature is $\left[{ }^{\circ} \mathrm{C}\right]$. The cooling rate $\dot{T}$ is taken as $0.17^{\circ} \mathrm{C} / \mathrm{s}$. The calculated relation between temperature and solid fraction is shown in Figure 16. The latent heat $L$ is $272 \mathrm{~kJ} / \mathrm{kg}$. Thermophysical and electrical properties are given in Table 1.

Table 1: Thermal and electrical properties of the considered UHS steel.

\begin{tabular}{ccccc}
\hline $\begin{array}{c}T \\
{\left[{ }^{\circ} \mathrm{C}\right]}\end{array}$ & $\begin{array}{c}\lambda \\
{[\mathrm{W} / \mathrm{m} / \mathrm{K}]}\end{array}$ & $\begin{array}{c}c_{p} \\
{[\mathrm{~J} / \mathrm{kg} / \mathrm{K}]}\end{array}$ & $\begin{array}{c}\rho \\
{\left[\mathrm{kg} / \mathrm{m}^{3}\right]}\end{array}$ & $\begin{array}{c}\sigma_{\text {elec }} \\
{\left[\Omega^{-1} \mathrm{~m}^{-1}\right]}\end{array}$ \\
\hline 25 & 38.9 & 447.0 & 7780.0 & $6.65 \times 10^{6}$ \\
100 & 40.5 & 479.0 & 7757.1 & $5.23 \times 10^{6}$ \\
200 & 41.0 & 526.0 & 7722.5 & $3.92 \times 10^{6}$ \\
300 & 41.6 & 582.0 & 7687.5 & $3.03 \times 10^{6}$ \\
400 & 40.6 & 640.0 & 7649.7 & $2.40 \times 10^{6}$ \\
500 & 39.5 & 710.0 & 7613.7 & $1.93 \times 10^{6}$ \\
600 & 37.5 & 810.0 & 7579.9 & $1.61 \times 10^{6}$ \\
700 & 33.9 & 1018.0 & 7556.0 & $1.30 \times 10^{6}$ \\
800 & 35.8 & 1051.0 & 7561.8 & $1.03 \times 10^{6}$ \\
900 & 24.8 & 610.0 & 7539.1 & $0.98 \times 10^{6}$ \\
1000 & 27.2 & 625.0 & 7494.1 & $0.95 \times 10^{6}$ \\
1100 & 29.1 & 641.0 & 7448.7 & $0.92 \times 10^{6}$ \\
1200 & 29.7 & 656.0 & 7408.0 & $0.89 \times 10^{6}$ \\
1300 & 30.7 & 672.0 & 7365.4 & $0.86 \times 10^{6}$ \\
1400 & 32.3 & 688.0 & 7325.7 & $0.83 \times 10^{6}$ \\
1437 & 33.6 & 710.0 & 7290.0 & $0.82 \times 10^{6}$ \\
1510 & 40.0 & 814.0 & 7030.9 & $0.76 \times 10^{6}$ \\
\hline
\end{tabular}

Regarding the mechanical behavior, the UHS steel is supposed to behave as an elastic-viscoplastic material, obeying the classical $J_{2}$ theory with isotropic linear hardening. The Young's modulus is taken 
from the Mizukami et al. ${ }^{[24]}$ :

$$
E[G P a]=968-2.33(T-273)+1.90 \times 10^{-3}(T-273)^{2}-5.18 \times 10^{-7}(T-273)^{3}
$$

Poisson's ratio is arbitrarily taken as 0.3 . Two different constitutive viscoplastic models have been considered in the present study.

\section{Additive model from Kozlowski et al. (model III) ${ }^{[25]}$ :}

This model corresponds to Eq. 17:

$$
\bar{\sigma}=\sigma_{y}+H_{\mathrm{evp}} \bar{\varepsilon}^{n}+K_{\mathrm{evp}} \dot{\bar{\varepsilon}}^{m}
$$

The material exhibits a plastic yield stress under which its behavior is purely elastic. This plastic yield stress is the sum of the initial yield stress $\sigma_{\mathrm{y}}$ and the strain hardening contribution $H_{\mathrm{evp}} \bar{\varepsilon}^{n}$. The constitutive parameters used here are taken from reference [25]. They are supposed to cover a wide range of austenitic plain carbon steels:

$$
\begin{gathered}
\sigma_{\text {y }}=0 \\
m=1 /\left(8.132-1.540 \times 10^{-3} T\right) \\
n=-0.6289+1.114 \times 10^{-3} T \\
H_{\text {evp }}=130.5-5.128 \times 10^{-3} T \\
K_{\text {evp }}=\left(\frac{1}{C} \exp \left(\frac{Q}{R T}\right)\right)^{m}
\end{gathered}
$$

where $C=46550+71400 c+12000 c^{2}, Q=371.2 \mathrm{~kJ} / \mathrm{mol}$. The carbon content $c$ is in [wt\%], and the stress, $H_{\text {evp }}$ and $K_{\text {evp }}$ is in [MPa].

\section{Model proposed by Han et al. ${ }^{[22]}$ :}

This model corresponds to Eq. 30:

$$
\bar{\sigma}=\frac{\bar{\varepsilon}^{n}}{\alpha} \operatorname{arsinh}\left[\left(\frac{1}{A} \exp \left(\frac{Q}{R T}\right)\right)^{m} \dot{\bar{\varepsilon}}^{m}\right]
$$

The corresponding material parameters used here are taken from Seol et al. ${ }^{[8]}$, who characterized a steel grade with a composition approaching the composition of the grade considered here: $0.14 \mathrm{wt} \% \mathrm{C}$, $0.40 \mathrm{wt} \% \mathrm{Si}, 1.28 \mathrm{wt} \% \mathrm{Mn}$. Their parameters are listed in Table 2. 
Table 2: Parameters value of Eq. 30, taken from Seol et al. ${ }^{[8]}$

\begin{tabular}{ccccc}
$A\left(\mathrm{~s}^{-1}\right)$ & $Q(\mathrm{~kJ} / \mathrm{mol})$ & $\alpha\left(\mathrm{MPa}^{-1}\right)$ & $m$ & $n$ \\
$1.192 \times 10^{10}$ & 422.9 & 0.0715 & 0.2038 & 0.1544 \\
\hline
\end{tabular}

In order to illustrate the differences between these two constitutive models, stress-strain curves have been plotted for a constant strain rate $0.001 \mathrm{~s}^{-1}$ and three different temperatures (Figure 17). It can be seen that there are significant differences between the calculated curves.

\section{Nomenclature}






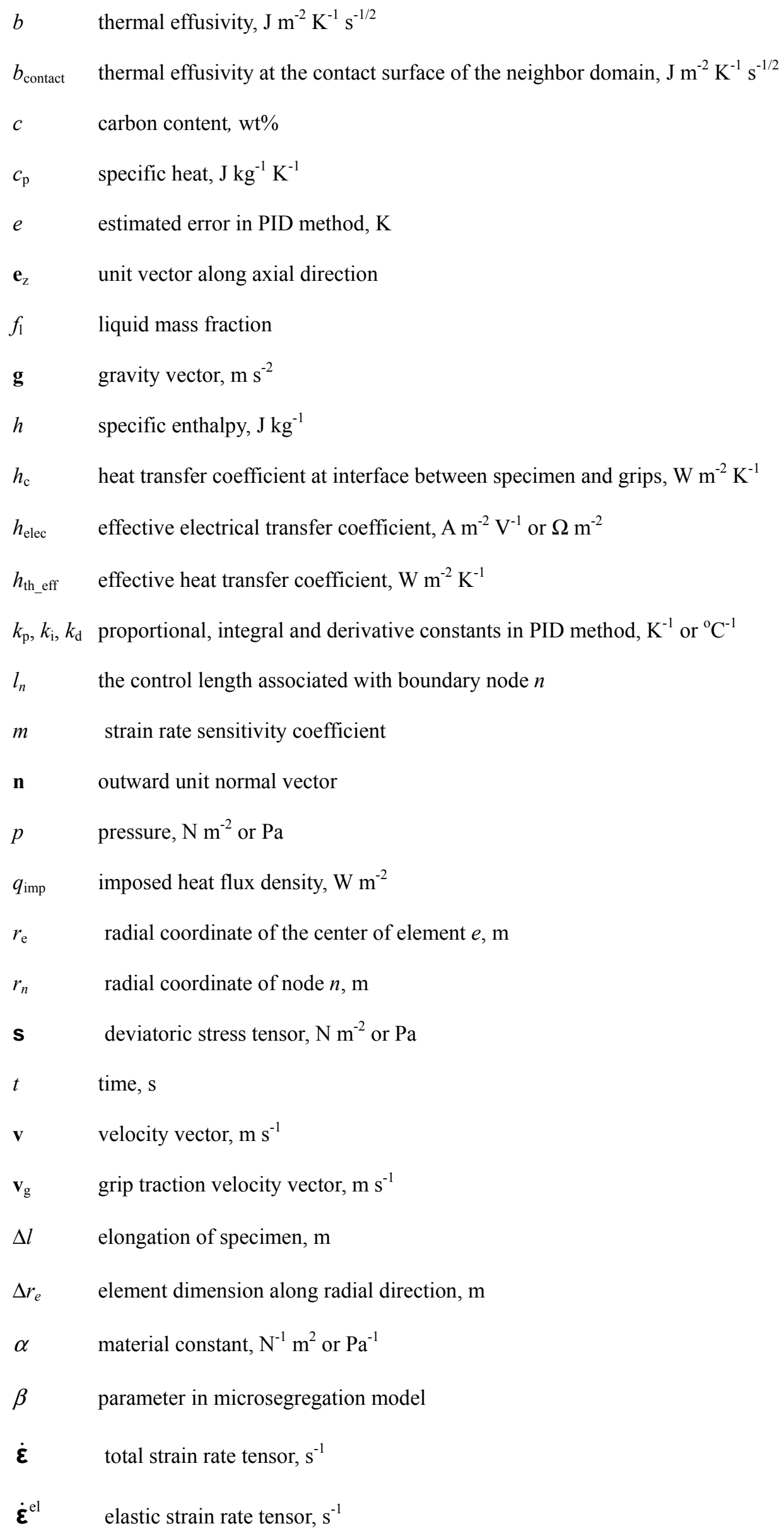


$\dot{\boldsymbol{\varepsilon}}^{\text {th }} \quad$ thermal strain rate tensor, $\mathrm{s}^{-1}$

$\dot{\boldsymbol{\varepsilon}}^{\mathrm{vp}} \quad$ irreversible (viscoplastic) strain rate tensor, $\mathrm{s}^{-1}$

$\dot{\bar{\varepsilon}} \quad$ von Mises equivalent strain rate, $\mathrm{s}^{-1}$

$\lambda \quad$ heat conductivity, $\mathrm{W} \mathrm{m}^{-1} \mathrm{~K}^{-1}$

$\rho \quad$ density, $\mathrm{kg} \mathrm{m}^{-3}$

$\phi \quad$ electrical potential, $\mathrm{V}$

$\phi_{\text {imp }} \quad$ imposed electrical potential, V

$\phi_{\text {contact }}$ local electrical potential at the contact surface of the neighbor domain, $\mathrm{V}$

$\sigma_{\text {elec }} \quad$ electrical conductivity, $\mathrm{A} \mathrm{V}^{-1} \mathrm{~m}^{-1}$ or $\Omega^{-1} \mathrm{~m}^{-1}$

$\boldsymbol{\sigma} \quad$ Cauchy stress tensor, $\mathrm{N} \mathrm{m}^{-2}$ or $\mathrm{Pa}$

$\bar{\sigma} \quad$ von Mises equivalent stress, $\mathrm{N} \mathrm{m}^{-2}$ or $\mathrm{Pa}$

$\sigma_{\mathrm{y}} \quad$ initial yield stress, $\mathrm{N} \mathrm{m}^{-2}$ or $\mathrm{Pa}$

$\sigma_{\mathrm{zz}} \quad$ axial stress component, $\mathrm{N} \mathrm{m}^{-2}$ or $\mathrm{Pa}$

$v \quad$ Poisson's ratio

$\chi_{\mathrm{p}} \quad$ penalty coefficient 


\section{References:}

1. D.G. Eskin, L. Katgerman: Metall. Mater. Trans. A, 2007, vol. 38A, pp. 1511-19.

2. D.J. Lahaie, M. Bouchard: Metall. Mater. Trans. B, 2001, vol. 32B, pp. 697-705.

3. S. Nagata, T. Matsumiya, K. Ozawa, T. Ohashi: Tetsu-to-Hagané, 1990, vol. 76, pp. 214-21.

4. Y.M. Won, T.J. Yeo, D.J. Seol, K.H. Oh: Metall. Mater. Trans. B, 2000, vol. 31, pp. 779-94.

5. M. Bellet, O. Cerri, M. Bobadilla, Y. Chastel: Metall. Mater. Trans. A, 2009, vol. 40, pp. 2705-17.

6. M. Rappaz, J.M. Drezet, M. Gremaud: Metall. Mater. Trans. A, 1999, vol. 30, pp. 449-55.

7. K. Kim, K.H. Oh, D.N. Lee: Scripta Materialia, 1996, vol. 34, pp. 301-07.

8. D.J. Seol, Y.M. Won, T.J. Yeo, K.H. Oh, J.K. Park, C.H. Yim: ISIJ Int., 1999, vol. 39, pp. 91-98.

9. M. Hojny, M. Glowacki: Steel Res. Int., 2008, vol. 79, pp. 868-74.

10. S.G.R. Brown, J.D. James, J.A. Spittle: Modell. Simul. Mater. Sci. Eng., 1997, vol. 5, pp. 539-48.

11. S.D. Norris, I. Wilson: Modell. Simul. Mater. Sci. Eng., 1999, vol. 7, pp. 297-309.

12. K. Solek, Z. Mitura, R. Kuziak: Proc. 3rd MIT Conference on Computational Fluid and Solid Mechanics, K.J. Bathe, ed., Massachusetts Institute of Technology, Boston, USA, 2005, pp. 1001-03.

13. M. Rappaz, M. Bellet, M. Deville: Numerical Modeling in Materials Science and Engineering, Springer Series in Computational Mathematics, Springer-Verlag, Berlin, Heidelberg, New York, 2003.

14. M. Bellet, V.D. Fachinotti: Comput. Meth. Appl. Mech. Eng., 2004, vol. 193, pp. 4355-81.

15. B.G. Thomas, M. Bellet: ASM Handbook vol. 15, Casting Division 4: Modelling and Analysis of Casting Processes, American Society of Metals, 2008, vol.15, pp. 449-61.

16. J. Lemaître, J.-L. Chaboche: Mechanics of Solid Materials, Cambridge University Press, United Kingdom, 1990.

17. O. Jaouen: Modélisation tridimensionnelle par éléments finis pour l'analyse thermomécanique du refroidissement des pièces coulées (Three-dimensional Finite element modelling for the thermomechanical analysis of the cooling of castings), Ph.D. Thesis (in French), Mines-ParisTech, 1998.

18. M. Bellet, O. Jaouen, I. Poitrault: Int. J. Num. Meth. Heat Fluid Flow, 2005, vol. 15, pp. 120-42. 
19. M. Bellet, F. Decultieux, M. Menai, F. Bay, C. Levaillant, J.L. Chenot, P. Schmidt, I.L. Svensson: Metall. Mater. Trans. B, 1996, vol. 27, pp. 81-99.

20. M. Bellet, A. Heinrich: ISIJ Int., 2004. vol. 44, pp. 1686-95.

21. G.A. Perdikaris: Computer Controlled Systems: Theory and Applications, Kluwer Academic Publishers, Dordrecht, The Netherlands, 1991.

22. H.N. Han, Y.G. Lee, K.H. Oh, D.N. Lee: Mater. Sci. Eng. A, 1996, vol. 206, pp. 81-89.

23. Y.M. Won, K.H. Kim, T.J. Yeo, K.H. Oh: ISIJ Int, 1998, vol.38, pp.1093-1099.

24. H. Mizukami, K. Murakami, Y. Miyashita: Tetsu-to-Hagané, 1977. 63(11), s562.

25. P.F. Kozlowski, B.G. Thomas, J.A. Azzi, H. Wang: Metall. Mater. Trans. A, 1992, vol. 23, pp. 903-18. 
Figures:

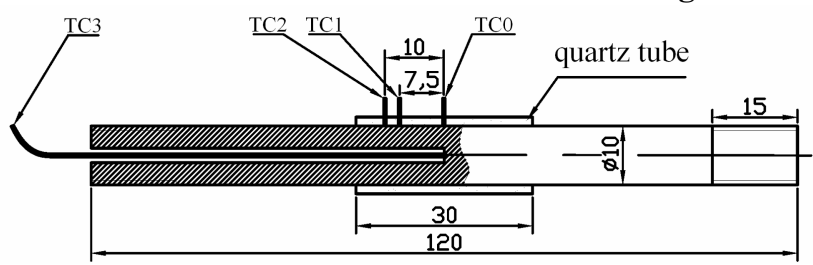

Fig.1a

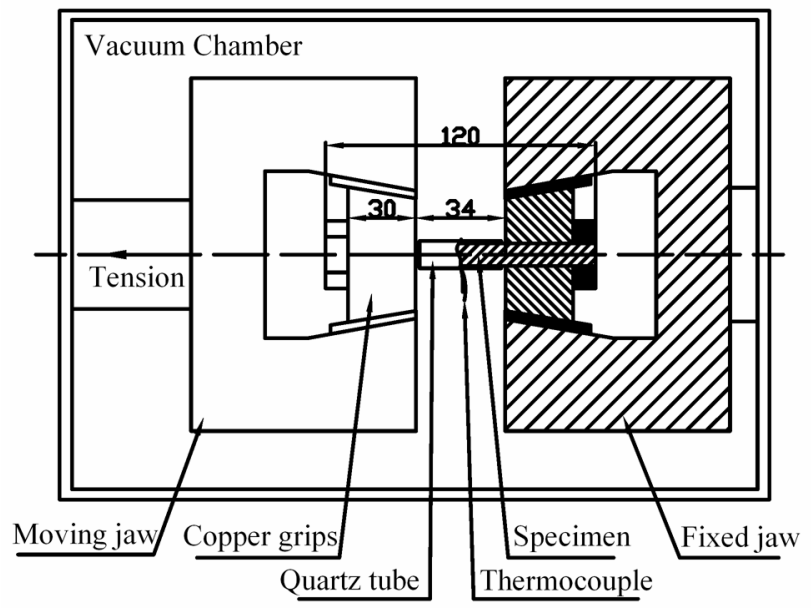

Fig. 1b

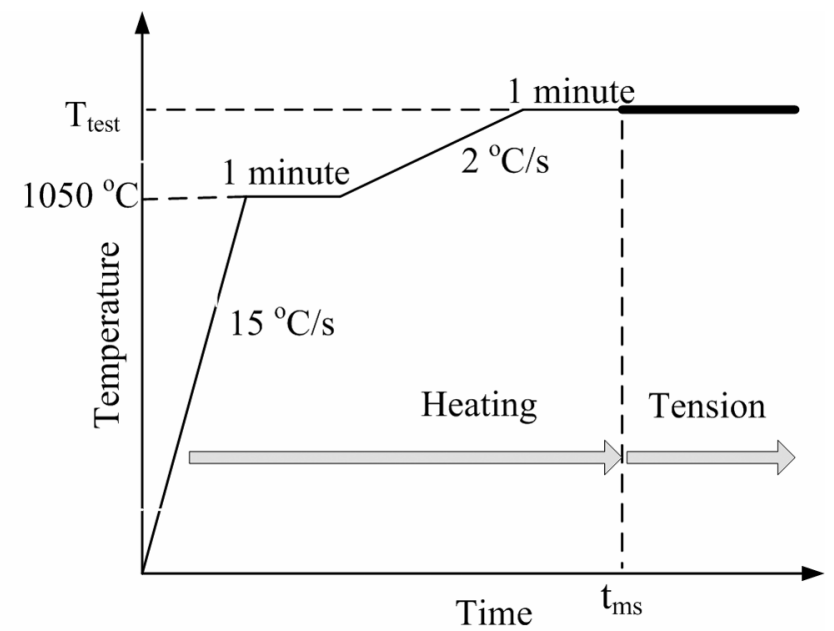

Figure 2

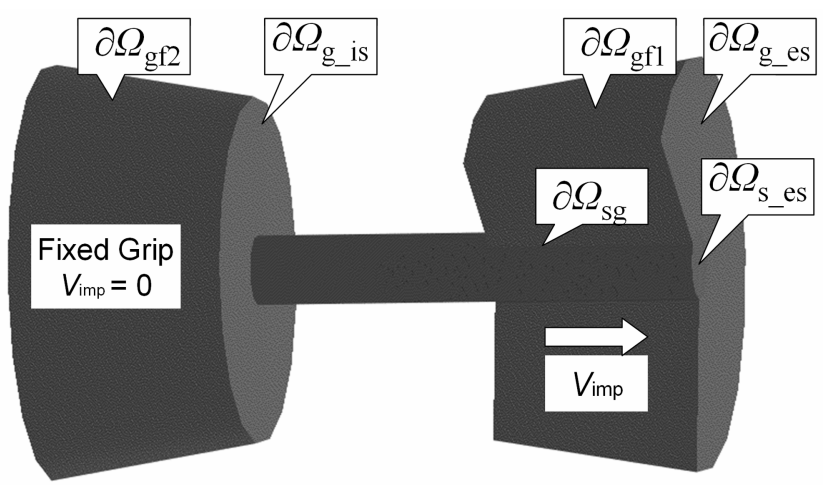

Figure 3 
Element and node numbers:

Specimen:

12893 elements, 6731 nodes

Grips:

3852 elements, 2034 nodes

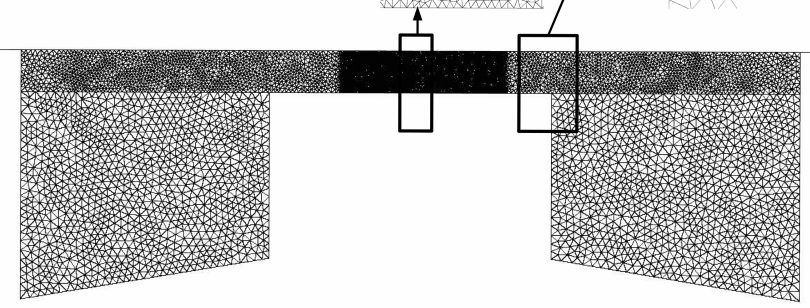

Fig 4

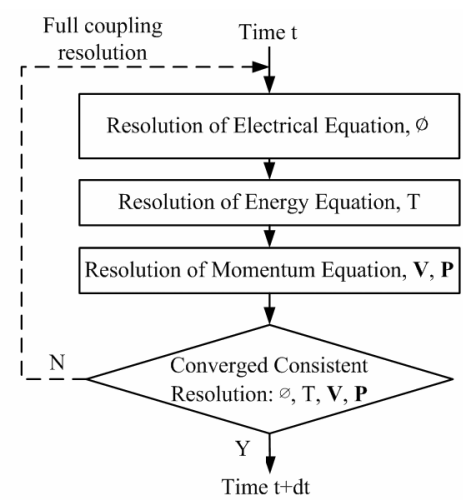

(a)

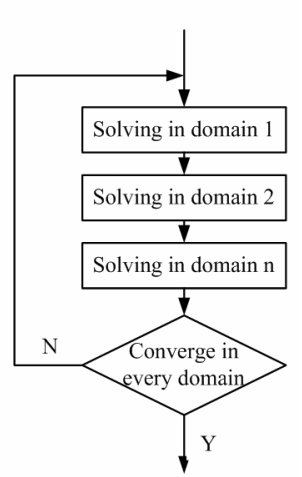

(b)

Fig 5

Electrical Potential, $\phi$

$\begin{array}{lllllllllll}0.673 & 0.606 & 0.538 & 0.471 & 0.404 & 0.336 & 0.269 & 0.202 & 0.135 & 0.067 & 0\end{array}$

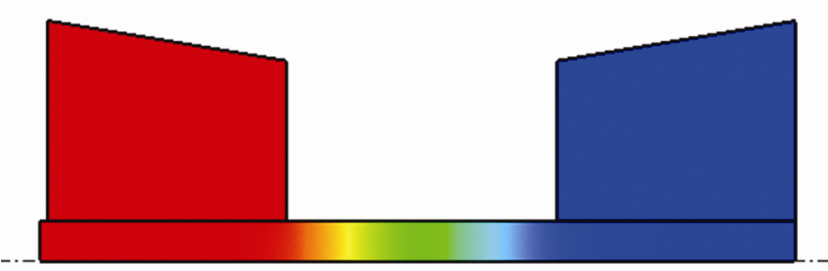

Fig. 6a 


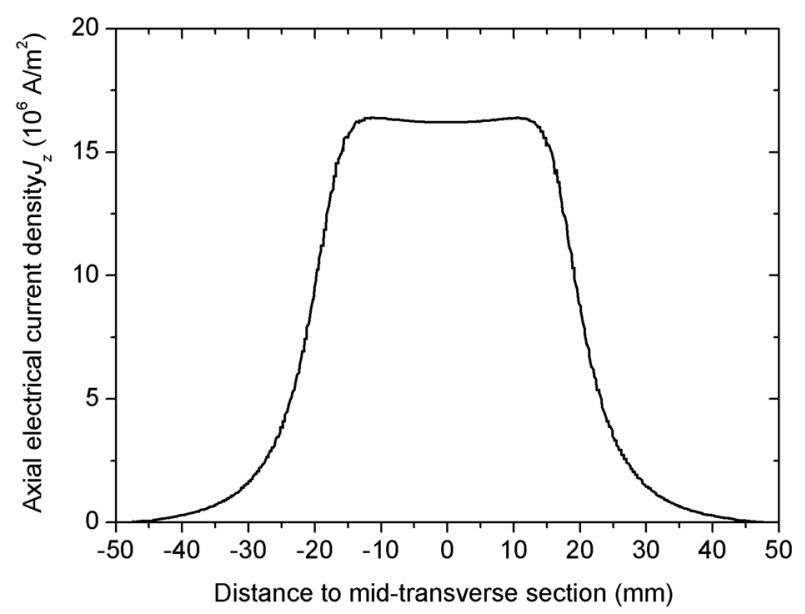

Figure 6b

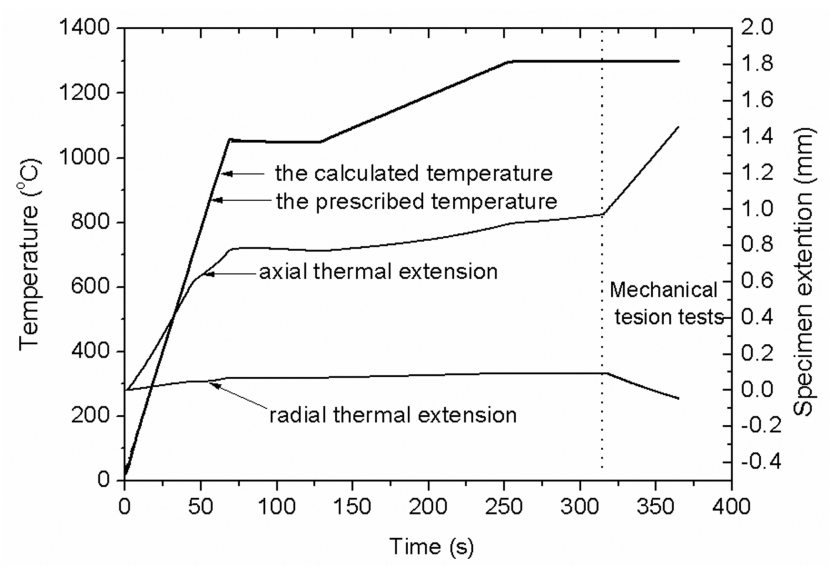

Figure 7

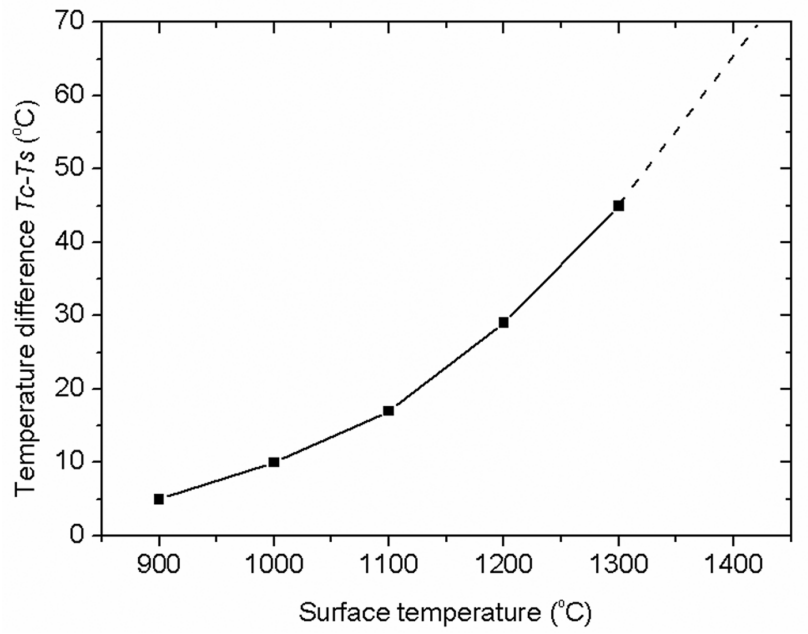

Figure 8 


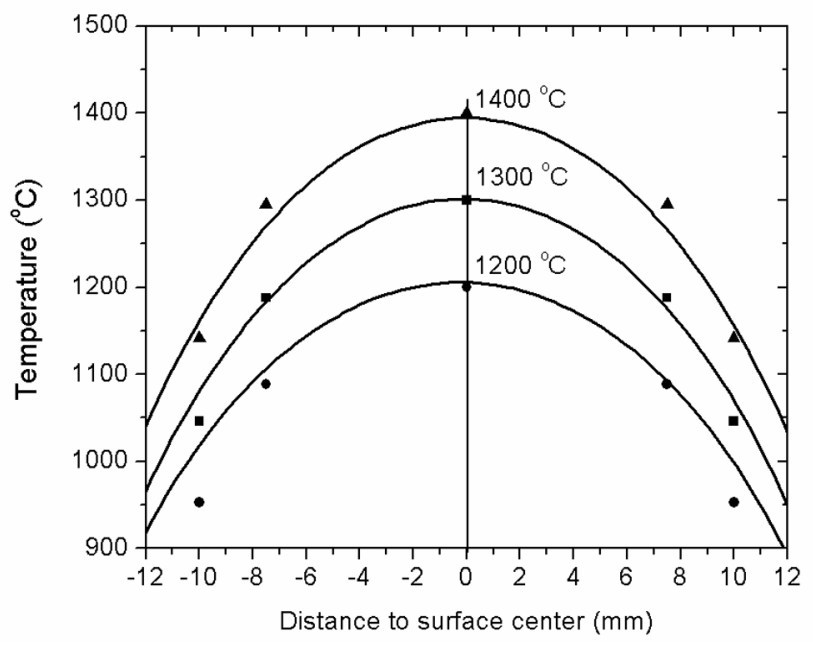

Fig 9a

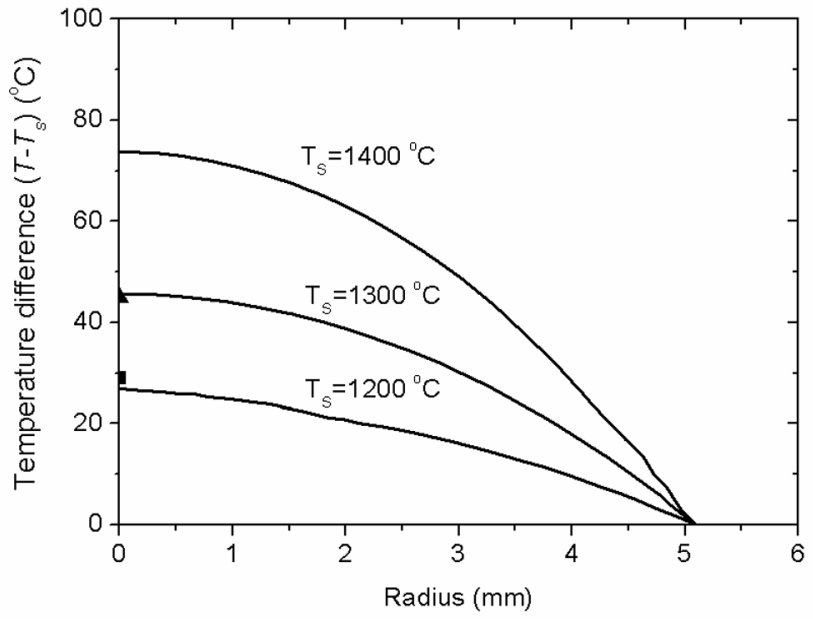

Fig 9b

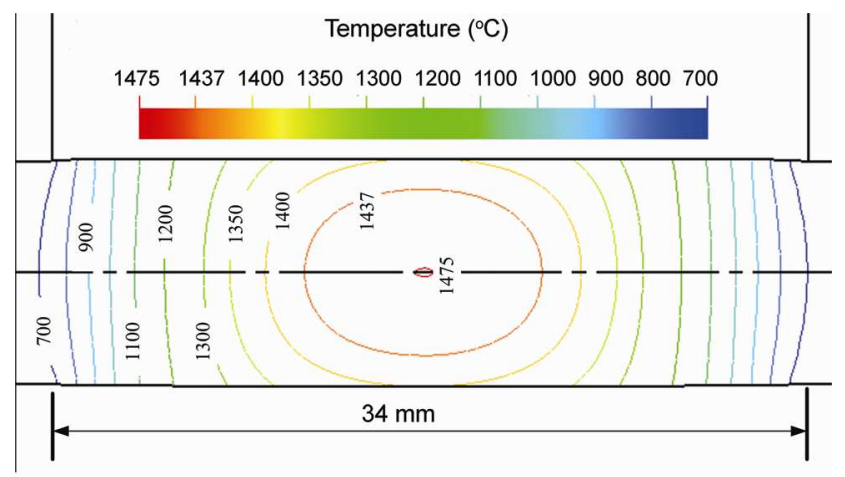

Fig 10a 


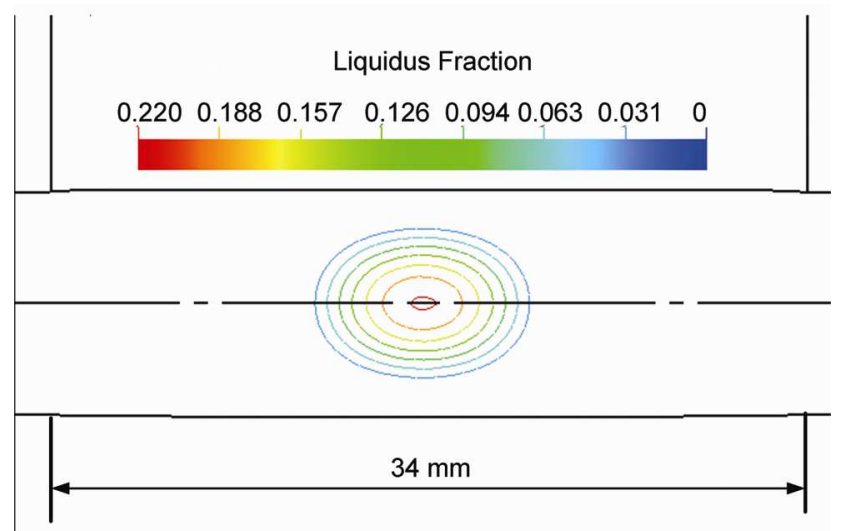

Fig $10 \mathrm{~b}$

$\bar{\sigma}(\mathrm{MPa})$

$\begin{array}{lllllllllll}495 & 446 & 396 & 347 & 297 & 248 & 198 & 149 & 99 & 50 & 0\end{array}$
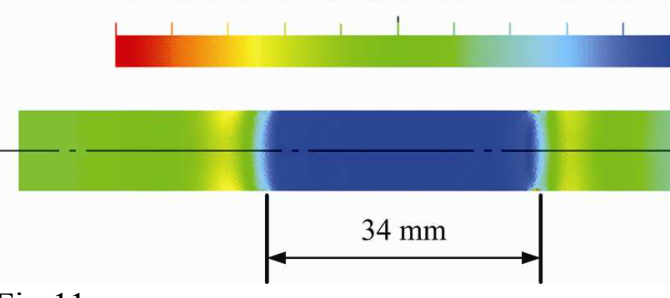

Fig 11a

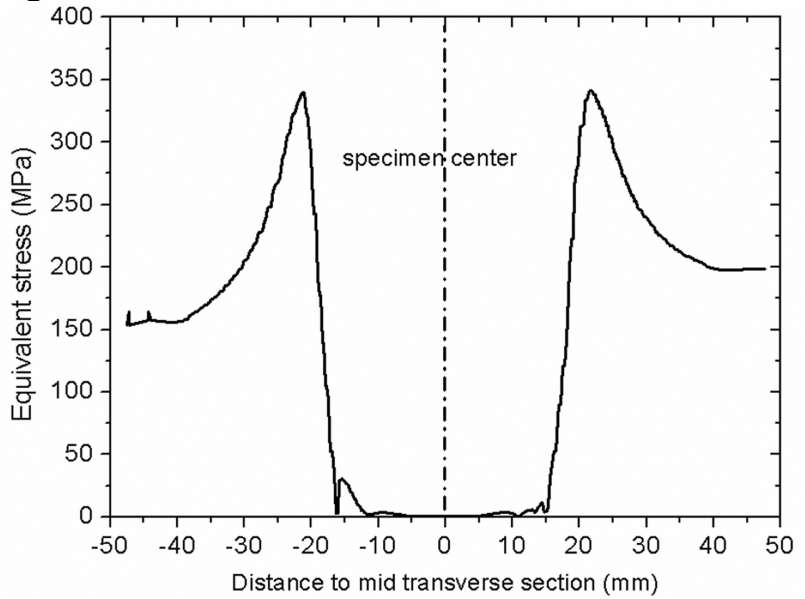

Fig $11 b$

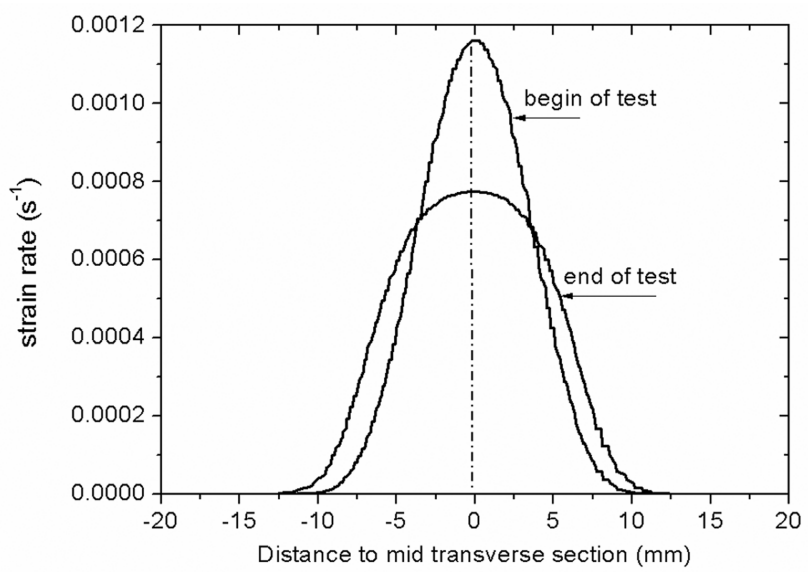

Fig 12a 


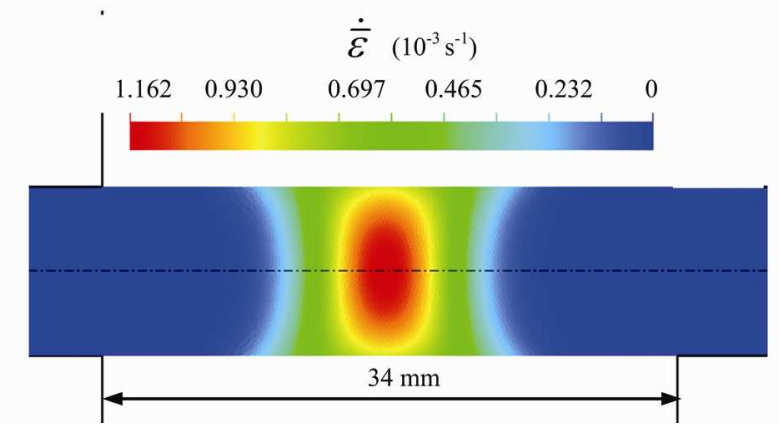

Figure 12b

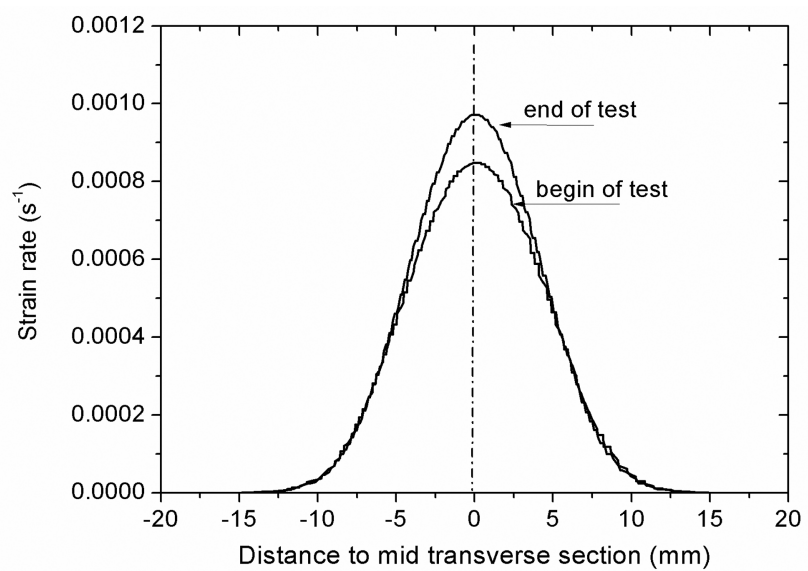

Fig 13a

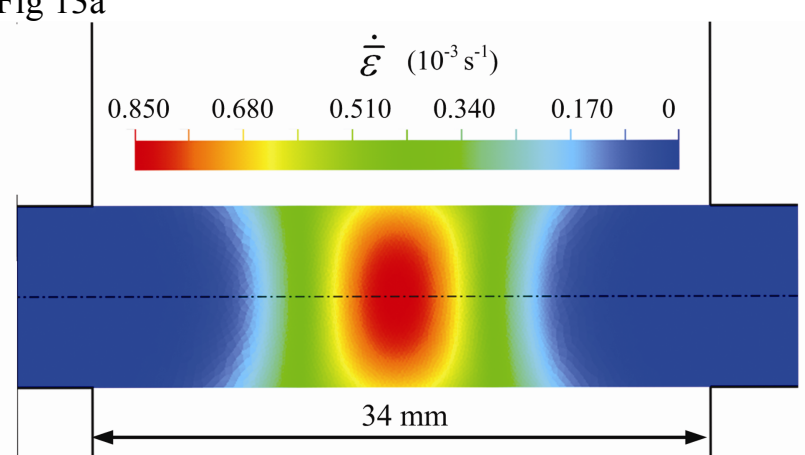

Fig $13 b$

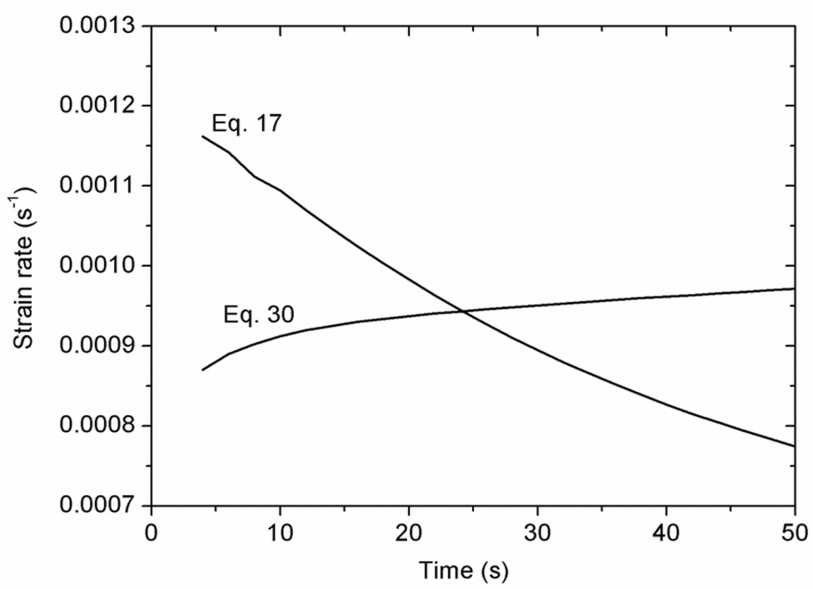

Fig 14 


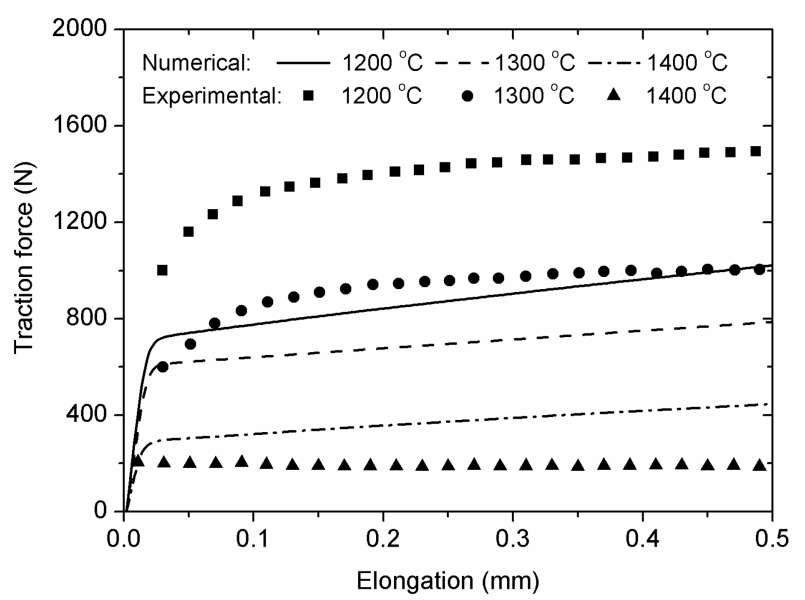

Fig 15

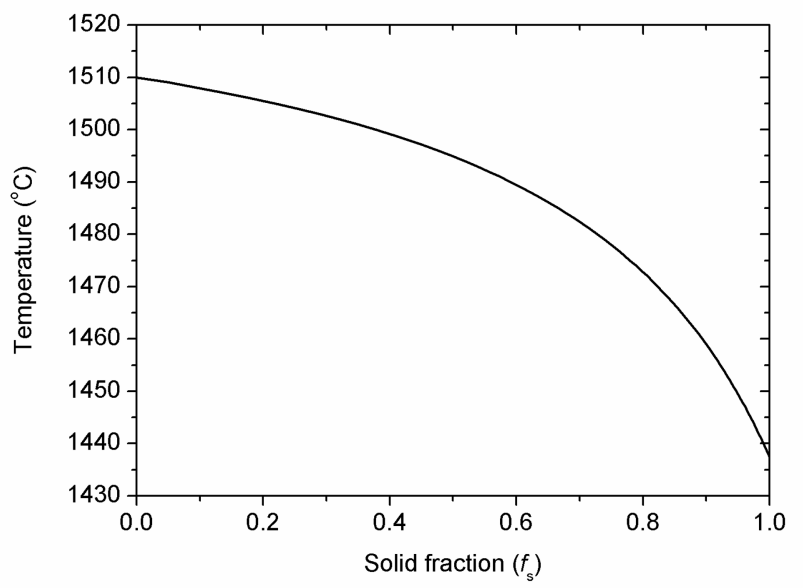

Fig 16

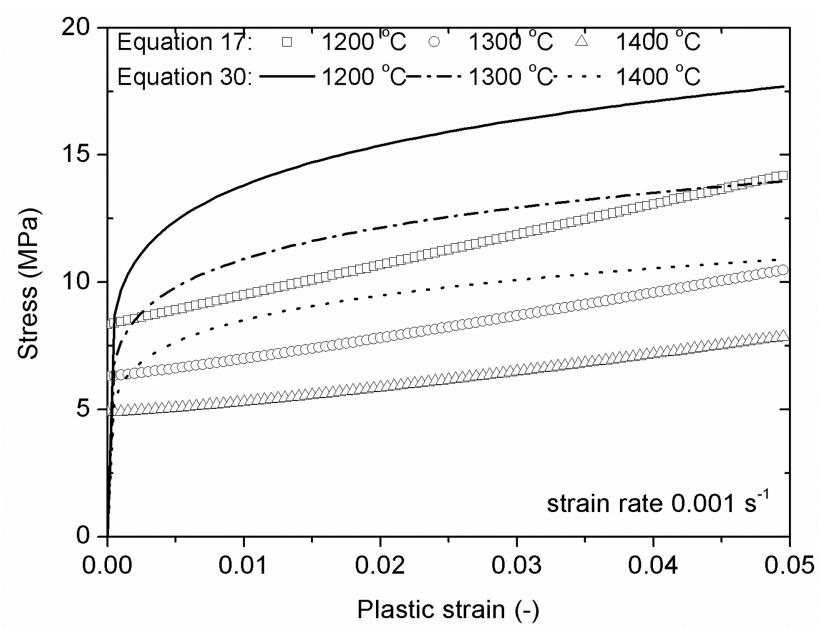

Fig 17 


\section{Figure List:}

Figure 1a-b: Schematics of Gleeble 1500D tensile testing system. (a) Temperature measurements of the cylindrical specimen in specially dedicated tests; (b) Section view of the tensile specimen installed in the machine.

Figure 2: Schematic diagram of the thermal-mechanical history for tensile tests.

Figure 3: Schematic geometrical model used for the modelling of Gleeble tensile tests

Figure 4: Finite element meshes of the specimen and Gleeble grips (linear triangular elements).

Figure 5: Multi-domain resolution strategy. (a) electrical, thermal and mechanical coupling resolution strategy; (b) multi-domain electrical or thermal resolution.

Figure 6a-b: (a) Electrical potential distribution in a longitudinal section of the tensile set-up; (b) electrical current density axial profile in the specimen.

Figure 7: Calculated and prescribed heating history, together with the evolution of the calculated axial and radial thermal expansions.

Figure 8: Measured radial temperature difference (core with respect to surface) in the medium transverse section of the specimen, as a function of surface temperature.

Figure 9a-b: Temperature distribution for three different nominal temperatures (a) calculated surface temperature profile in the axial direction together with experimental measurements; (b) calculated radial temperature distribution in the mid transverse section. Superimposed are two measurements at position TC3 (center of specimen).

Figure 10a-b: (a) Temperature and (b) liquid fraction distributions in a longitudinal section of the working zone of the specimen, for a nominal surface temperature $1400{ }^{\circ} \mathrm{C}$.

Figure 11a-b: Distribution of the von Mises equivalent stress, due to thermal dilatation, before mechanical tension. (a) equivalent stress distribution in the longitudinal section of the specimen (b) 
equivalent stress profile along symmetry axis.

Figure 12a-b: Calculated distribution of the equivalent strain rate $\dot{\bar{\varepsilon}}$ in the specimen at nominal testing temperature $1200{ }^{\circ} \mathrm{C}$ and for a constant velocity of the moving grip $V_{\text {imp }}=0.01 \mathrm{~mm} / \mathrm{s}$. (a) axial profiles of $\dot{\bar{\varepsilon}}$ at core at the beginning and in the end (50 s) of the test; (b) distribution map of $\dot{\bar{\varepsilon}}$ at the beginning of the mechanical test $\left(\right.$ maximum $\left.=1.16 \times 10^{-3} \mathrm{~s}^{-1}\right)$.

Figure 13a-b: strain rate and strain axial distributions, calculated by Eq. 30, in the specimen at nominal testing temperature $1200{ }^{\circ} \mathrm{C}$ and for a constant velocity of the moving grip: $V_{i m p}=0.01 \mathrm{~mm} / \mathrm{s}$. (a) strain rate axial profiles at core at the beginning and ending (50 s) of mechanical tests; (b) strain rate distribution map at the beginning of mechanical tests (maximum $\left.=0.85 \times 10^{-3} \mathrm{~s}^{-1}\right)$.

Figure 14: Evolution of the maximum of strain-rate (found at the center of the specimen) during the tensile test, for the additive model (Eq. 17) and the hyperbolic sine model (Eq. 30).

Figure 15: Comparison between the experimentally measured and the calculated traction force vs elongation curves during Gleeble tension tests with imposed grip velocity $0.01 \mathrm{~mm} / \mathrm{s}$ and three nominal temperatures. Calculations are done with the additive constitutive model.

Figure 16: The calculated relation between solid fraction and temperature for the steel.

Figure 17: Plotted stress-strain curves of eq.17 with parameters taken from reference [25] and of eq.30 with parameters taken from reference [8]. 